\title{
Importancia de la poesía infantil en el plan lector
}

Heriberto Tejo Gómez

\section{La poesía infantil}

Empezaré diciendo que la poesía, a diferencia de otros géneros, no solo se lee, sino que también se escucha, se recita y se canta. Si el encuentro con la poesía para niños se produce en buenas circunstancias y con excelente disposición, nuestros niños se podrán dar cuenta de que la poesía es una fuente de sentimientos y emociones, de nuevas ideas y de vivencias insospechadas.

La poesía infantil, es bueno aclarar, no es esa poesía hecha de diminutivos ni esa poesía ñoña y superficial carente de armonía y de capacidad de emocionar o conmover. La poesía infantil, como señala Pedro Cerrillo, es sencillamente la poesía escrita para niños, es decir, para esos lectores que todavía están en la etapa de desarrollo y formación aunque también puedan acceder a otros poemas que sean de su agrado o interés y no hayan sido escritos expresamente para ellos.

En el Perú hay muchos poetas importantes que en algún momento de sus vidas escribieron poesía para niños, aunque no los conozcamos como poetas infantiles como, por ejemplo, José María Eguren, Mario Florián, Enrique Peña Barrenechea, Javier Sologuren, Arturo Corcuera. Hay otros poetas, en cambio, que son conocidos precisamente por su dedicación al mundo de la poesía para niños, aunque algunos de ellos también hayan escrito poesía para adultos como Luis Valle Goicochea, Abraham Arias Larreta, Catalina Recavarren, Jorge Ortiz Dueñas, Jorge Díaz Herrera, Luis Alberto Calderón, Jorge Eslava, Heriberto Tejo.

En todos ellos, su poesía para niños se relaciona de alguna manera con la esencia de la poesía popular, con la poesía de transmisión oral: repeticiones, versos cortos, estribillos, rimas reguladas, elementales símbolos, personificaciones, comparaciones, metáforas, y es que precisamente estos elementos enhebrados con ritmos propios son los que caracterizan a la poesía infantil. 


\section{Hitos de la poesía infantil peruana}

En el itinerario de la poesía infantil peruana sobresalen nítidamente diez creadores que debido a su sensibilidad y lenguaje fresco y directo, han sabido llegar a los niños y niñas ofreciendo una poesía de calidad, con capacidad de conmover, emocionar y despertar su imaginación y asombro. Los premios nacionales e internacionales y los reconocimientos obtenidos por su valiosa y meritoria creación lo sustentan.

\section{a) Dos fundadores}

El poeta Luis Valle Goicochea con los poemarios Las canciones de Rinono y Papagil (1932), El sábado y la casa (1932) y Marianita Coronel (1943, publicado en 1974), y el poeta Abraham Arias Larreta con el poemario Rayuelo, versos infantiles (1939), se consideran definitivamente los fundadores de la poesía infantil peruana.

Sus libros constituyen los primeros esfuerzos poéticos para configurar una obra personal para niños, teniendo como primeros y grandes referentes la poesía fresca y musical con singular mirada infantil de José María Eguren, y la primera poesía cálida y humana de César Vallejo.

\section{b) Crecimiento}

En las siguientes décadas, la lírica infantil recuperó impulso y encontró su expresión más prístina y original con la sugerente y valiosa propuesta de cuatro grandes autores: Jorge Ortiz Dueñas, con sus poemarios La canción menuda (1945) y Plumas del nido(1982); Mario Florián con su obra Poemas para niños (1956) y la Antología de poesía para niños (1961), la primera de su género en el Perú; Arturo Corcuera con los poemarios Noé Delirante (1963), Fiesta de sorpresas (1996), El libro de las adivinanzas (1997) y La flauta kikirikí (2006); y Jorge Díaz Herrera con las obras Parque de Leyendas (1977), El gato de los siete oficios (1984) y Poemas para cantar, reír y contar (1984).

Sus logrados y sugerentes poemas difundidos en textos escolares y antologías, le dieron un nuevo aire a la poesía infantil.

\section{c) Consolidación}

Es en la década de los años ochenta que aparecen autores de fina sensibilidad estética que iniciarán un recorrido de alto impacto en la poesía infantil peruana, abriendo múltiples caminos para las nuevas generaciones. Ellos son: Javier Sologuren con el poemario Retornelo (1986); Carlota Carballo de Núñez con el poemario Poesías para niños (1986); Jorge Eslava con el poemario Caballo de madera y otras canciones (1984); Luis Alberto Calderón con los poemarios Trinos del alba (1987), Travesías de la infancia (1992) y Caminitos de Paz (1998); y Heriberto Tejo con los poemarios Canto de gorriones (1986), Magia de primavera (1989), Camino del Arco Iris (1991), Hola, Caracol (1997) y Mariposas azules (2008).

Otros autores significativos de nuestra lírica infantil que aportan con logrados poemas 
publicados en antologías y textos escolares son, por ejemplo, Catalina Recavarren, Rosa Cerna Guardia, Francisco Izquierdo Ríos, Gerardo de Gracia, Gerardo García Rosales.

Son estos autores peruanos, por lo tanto, los que mejor pueden crear una corriente lírica en la poesía para niños: sus formas tradicionales y nuevas, la sonoridad y musicalidad de los versos, el sentido del juego y el disparate, las imágenes sensoriales, el sentimiento intenso, el amor a la naturaleza, en fin, la sorpresa y belleza de lo cotidiano.

Ojalá, en los próximos años, se evidencie un marcado interés en las editoriales y en las escuelas, por acercar a los niños, con bellas ilustraciones, estos grandes autores de la poesía infantil peruana. Nuestros niños y niñas se lo merecen. El gusto por la poesía se forma paso a paso teniendo reiteradas experiencias y vivencias con buena poesía.

\section{Leer poesía en el aula}

La presencia de la poesía infantil en el plan lector, tanto en el sector editorial como en el ámbito escolar, prácticamente es inexistente; quizás sea porque para muchos maestros y padres de familia la poesía es algo distante e inaccesible, incluso asunto de poca importancia. Nada más alejado de la verdad, pues como dice el escritor Sergio Andricaín (2016), la poesía educa la sensibilidad, desarrolla la expresión y creatividad y fomenta el espíritu crítico desde las primeras edades.

Justamente, por ello, es tan importante que la poesía esté dentro de todo plan lector y se lleve a las aulas desde los primeros años con la misma relevancia conque llevamos otras lecturas, pues es una posibilidad expresiva más, con capacidad para conmover, emocionar, pensar o sentir de manera diferente.

La lectura de cuentos procura en los niños placer y entretenimiento, los libros informativos les dan conocimiento, los periódicos y revistas los informan, y la poesía, iqué les ofrece al leerla en el aula? Ciertamente, tendríamos que decir que, por lo general, los buenos poemas, la verdadera poesía, no les enseña nada útil, nada concreto en sentido tradicional, pero se sabe que el encuentro frecuente con la poesía humaniza los sentidos del niño, enriquece su posibilidad de expresión, propicia un goce en la apreciación de la belleza, invita a pensar, a mirar el mundo de otra manera.

La poesía solo tendrá sentido en la escuela cuando el acercamiento a ella esté desprovisto de ese carácter práctico de enseñar o transmitir un conocimiento o una moraleja. Como bien dice Sergio Andricaín, la poesía en el aula tendrá su verdadero sentido cuando los niños y niñas lean poemas por gusto, por el placer de leer, sin esperar que después de leer unos versos, sean más sabios o más buenos, sino más sensibles y más plenos como seres humanos.

Leer un poema es encontrarse con la belleza, con el juego, con lo transcendente, con el asombro. Desconfiemos como mediadores de poesía, de los poemas escritos para enseñar a los niños que bañarse todos los días es muy importante para la salud, o que hay que ceder el asiento a las personas mayores cuando viajamos. Muchos maestros piensan que la poesía es compleja y difícil de entender. Pero eso no es cierto. Todas las personas, niños o adultos, podemos acceder a la poesía, solo se necesita un entrenamiento de la sensibilidad y la inteligencia en los 
lenguajes de la poesía, pues la poesía más que explicarla o entenderla, hay que sentirla. De ahí que el mejor momento para acercarse a la poesía y disfrutarla sea la infancia, la etapa poética por excelencia.

\section{Poesía infantil, imprescindible en el plan lector}

Leer y apreciar la poesía infantil supone, como ya hemos dicho, una sensibilidad especial que los maestros debemos desarrollar en los niños, un gusto por la magia de las palabras, por los sonidos y ritmos sencillos que hacen que poco a poco vayan acercándose a ese mundo peculiar de la armonía poética. Pero no debería resultar difícil para los maestros y demás mediadores, pues los niños por naturaleza gustan de la poesía. Desde que nacen, disfrutan con los ritmos y sonidos de las palabras y las canciones rimadas, Ahora bien, para que gocen y aprecien la poesía, es necesario que el maestro o mediador se la acerque, que los ponga en contacto con los poemas de una manera natural, desprovista de la pedagogía mal entendida. Es decir, que haga de la palabra poética un elemento lúdico y estético que emocione a quien la lea.

Un plan lector que no considere entre sus lecturas libros de poesía infantil es, simplemente, un plan deficiente e injusto que socaba la formación estética de los niños. Ellos necesitan leer y escuchar poesía, disfrutar con las palabras, emocionarse y vibrar con la belleza que desliza por los versos.

Si cultivamos, por lo tanto, mediante un plan lector responsable, la sensibilidad en los niños desde los primeros años, tendremos ciudadanos más comprometidos y cívicos, y sobre todo más humanos. La poesía, como ya hemos dicho, mejora a las personas, embellece la mirada, despierta la imaginación, y nos permite soñar mundos nuevos más justos y solidarios.

\section{REFERENCIAS}

CERRILLO, Pedro (2010): ¿Dónde está el niño que yo fui? Poemas para leer en la escuela. Madrid: Ediciones Akal.

ANDRICAíN, Sergio y Antonio Orlando Rodríguez (12016): Escuela y poesía. ¿Y qué hago con el poema? Cuenca: Ediciones de la Universidad de Castilla-La Mancha.

ANDRICAÍN, S. Y CERRILLO, P. (2015): Dos orillas y un océano: 25 autores iberoamericanos de poesía para niños y jóvenes. Cuenca: Ediciones de la Universidad de Castilla-La Mancha.

GONZÁLEZ VIGIL, Ricardo (2005): Poesía peruana para niños. Lima: Alfaguara. 


\section{POEMAS DE HERIBERTO TEJO}

\section{De Mariposas azules}

\section{Luna gitana}

Luna de azúcar,

luna encantada.

iQué alegría verte

tras de mi ventana

vestida de novia,

de novia y tan guapa!

(En las tardes lila,

en las noches malva,

y en las mañanitas

color de retama).

Luna furtiva,

luna gitana.

Un toro de viento

pasa y te mancha.

Pasa y de tizne

llena tu cara.

iQue venga la lluvia,

que lave tu cara

y fije tu pelo

con clavitos de agua!

Luna de azúcar,

luna encantada. 


\section{Platero en la noche de carnaval}

Platero, como era blanco

y no tenía disfraz,

creyó que comiendo flores

luciría de colores

la noche de carnaval.

Tantas flores comió

y tantas las veces,

que su anhelo se cumplió

pronto y con creces.

Y ahí lo vieras a Platero

la noche de carnaval

bailando huayno y tondero,

marinera y alcatraz,

con sus orejas de malva,

la cola de tulipán,

verdes las patas de alante,

rojas las patas de atrás,

y la barriga amarilla

de tanta flor de azafrán.

Platero, lindo Platero,

arlequín de la ilusión,

iquién te pudiera llevar

pintado en el corazón! 


\section{Puentes}

Entre tanta gente

yo construyo puentes

para que me encuentres.

Puentes de ladrillos

para que me encuentres

entre mis amigos.

Puentes de madera

para que me encuentres

de todas maneras.

Puentes de concreto

para que me encuentres

esté vivo o muerto.

Entre tanta gente

yo construyo puentes

para que me encuentres. 


\section{De Hola, caracol}

\section{La ballena feliz}

-Dime ballenita,

¿por qué estás feliz?

-Porque tengo un hijito

gracioso y feliz.

-iAy, ballena loca,

loca de alegría!

iJugar con tu hijito

sí me gustaría!

-iAy, niñito loco,

loco de remate!

¿Jugar con mi hijito?

iVaya disparate!

\section{Magia de primavera}

-Buenos días, Mariquita.

-Buenos días, Caracol.

- ¿Pasó el amor por tu casa?

- ¿Por mi casa? iNo señor!

-Yo vivo sola en un hongo.

-Yo solo bajo una col.

-iQué lindo! iQué lindo día!

-iQué lindo con tanto sol!

-iPrimavera está llegando!

- ¿Primavera? iYa llegó!

-Adiós, Mariquita linda.

-Adiós, Caracol, col, col. 


\title{
Palomita de maíz
}

\author{
Salta, salta \\ palomita, \\ palomita de maíz; \\ que si saltas \\ de la ollita \\ cuando acerco \\ la nariz, \\ diré a todos \\ que estás viva, \\ palomita de maíz.
}

\section{De La leve brisa del jacarandá (Inédito)}

\section{Vaivén de la sirenita}

La sirenita en la arena

viene y se va.

Viene y se va con las olas

viene y se va.

Viene y se va con la espuma

viene y se va.

De pronto

un niño

se acerca...

Y la sirenita se va.

Se va,

se va con el niño...

Algún día volverá. 


\section{Juegos peligrosos}

La niña juega a ser reina.

El niño a ser un guerrero.

Sobre la tarde, la brisa.

Sobre la brisa..., los sueños.

La niña juega a ser hada.

El niño a ser un velero.

Sobre la tarde, la brisa.

Sobre la brisa..., el fuego.

¡Allá replica un disparo!

¡Acá resuena un estruendo!

Sobre la tarde, la brisa.

Sobre la brisa..., el miedo.

¡Ay, que se rompe la tarde!

¡Ay, que se calla el silencio!

Malheridas, dos palomas

se desangran en el cielo. 


\section{La ventana}

Estaba la niña triste

mirando por la ventana

y en el aire, bajo el agua,

pegadito a su mirada.

-Tengo frío, tengo frío,

-le decía- y callaba.

La luna blonda en el cielo

de reojo los miraba.

Entre el cristal de la noche

los dos niños se abrazaban.

-Tengo frío, tengo frío,

-le decía- y callaba.

(En el campo, junto al fuego,

un grillo azul susurraba). 


\section{De Para dibujar un sueño (Inédito)}

\section{Para dibujar un sueño}

Para dibujar un sueño

solo tienes que cantar

y estar despierto.

Cantarle al sol,

a la brisa,

a las pequeñas

cosas, al

silencio.

Amigo,

para dibujar un sueño

(este es mi secreto)

solo tienes que callar

y escuchar

por dentro.

\section{Para dibujar un niño}

Para dibujar

un niño

(o una niña,

si deseas),

empieza

simplemente

por la cabeza.

Una cara redondita,

dos ojos, 
dos orejas,

una nariz chiquitita,

la boca muy sonriente,

poco cuello,

mucha frente,

y el cabello...

corto o largo

como tú bien lo desees.

Luego dibuja el tronco.

Un tronco largo,

sin ramas,

vestido de ropa blanca

con un brazo a cada lado

y las piernas separadas.

Algo más.

Que pise bien sobre el suelo.

Es un niño inteligente,

como lo era su abuelo.

Tiene las manos abiertas

y sueña...

sueña

con un mundo nuevo.

\section{Para dibujar mi país}

Un mural de mi país

con la costa,

la sierra

y la selva,

se dibuja de esta manera: 
Dos montañas nevadas,

un ancho valle,

y tres lindas casitas

(cada una con su banderita).

Arriba

un sol

un cóndor y un avión.

Abajo

un camino,

una niña y un niño.

Mucha agua a la izquierda,

muchos árboles a la derecha.

Aquí y allá

una llama,

un tucán,

muchas mariposas...

Dibuja también

una flor,

una linda tortuguita,

dos hormigas,

un caracol.

Y, rodeándolo todo,

dibuja con maestría

un gran corazón.

Un corazón

rojo y blanco.

El corazón

de todos los peruanos. 